\title{
Exercise capacity and pulmonary function in individuals with leprosy
}

\author{
Capacidade funcional de exercício e função \\ pulmonar em indivíduos com hanseníase
}

\section{Marcelo Taglietti ${ }^{[a]}$, Celeide Pinto Aguiar Peres ${ }^{[b]}$}

[a] Master in Bioscience and Health at Universidade Estadual do Oeste do Paraná, physical therapist, professor at Faculdade Assis Gurgacz, Cascavel, PR - Brazil, e-mail: marcelotaglietti@gmail.com

[b] Doctor in Medicine and Health Sciences at Universidade Estadual de Londrina, physical therapist, professor at Universidade Estadual do Oeste do Paraná, Cascavel, PR - Brazil, e-mail: lumarina@certto.com.br

\section{Abstract}

Introduction: In Brazil 23\% of leprosy patients have some type of physical disability after discharge. The impact on the respiratory system and correlation with functional exercise capacity is still unknown. Objective: To correlate the functional exercise capacity and pulmonary function in individuals with leprosy sequelae. Materials and methods: We evaluated 20 subjects and 25 controls by sensory evaluation, muscle strength, graduate the grade of physical disability followed by pulmonary function tests with spirometry and manovacuometry, besides the functional exercise capacity through the six minute walking distance (6MWD). Results: The majority (75\%) of the subjects showed physical disability grade 1. The mean of the maximal inspiratory pressure were below than normal $-71 \pm 31 \mathrm{cmH}_{2} 0$ and maximal expiratory pressure $+89 \pm 22 \mathrm{cmH}_{2} 0$. Spirometric values presented measures within normal value. The functional exercise capacity found a reduced value with a distance of $404 \pm 92 \mathrm{~m}$. Positive and statistically significant correlation between the inspiratory pressures with 6MWD $(r=0.49, \mathrm{p}=0.025)$ and, similarly, expiratory pressure $(\mathrm{r}=0.53, \mathrm{p}=0.004)$. The same evidence is found in maximal respiratory pressures of individuals in grade 1 with significant correlations $(r=0.52, p=0.036)$ and $(r=0.51, p=0.042)$. Conclusion: Individuals with leprosy sequelae had impaired respiratory muscle strength and functional 
exercise capacity. Maximal respiratory pressures are presented as an independent factor in the change in performance in the functional exercise capacity.

Keywords: Leprosy. Exercise. Pulmonary functional test.

\section{Resumo}

Introdução: No Brasil 23\% dos pacientes com hanseníase apresentam algum tipo de incapacidade física após a alta. $O$ impacto sobre o sistema respiratório e correlações com a capacidade funcional de exercício ainda é desconhecido. Objetivo: Correlacionar a capacidade funcional de exercício com a função pulmonar de indivíduos com sequelas de hanseníase. Materiais e métodos: Foram avaliados 20 indivíduos e 25 controles através de avaliação sensorial, força muscular dos membros e face, graduado o grau de incapacidade física e, seguido de testes de função pulmonar com espirometria e manovacuometria, além da capacidade funcional de exercício através do teste de caminhada em seis minutos (TC6). Resultados: A maioria (75\%) dos indivíduos apresentou grau de incapacidade física 1. A média das pressões respiratórias máximas encontrou-se abaixo da normalidade com $\mathrm{PI}_{\text {máx }}-71 \pm 31 \mathrm{cmH}_{2} \mathrm{O}$ e $\mathrm{PE}_{\text {máx }}+89 \pm 22 \mathrm{cmH}_{2} \mathrm{O}$. Os valores espirométricos apresentaram medidas dentro dos valores de normalidade. A capacidade funcional de exercício encontrou-se reduzida apresentando média de distância percorrida de $404 \pm 92 \mathrm{~m}$. Correlação positiva e estatisticamente significativa entre a $P_{\text {máx }}$ com a distância percorrida no TC6 ( $r=0,49$ e $p=0,025)$ e, da mesma forma, a PE $E_{\text {máx }}(r=0,53$ e $p=0,004)$. Foram encontrados. A mesma evidência é encontrada nas pressões respiratórias máximas dos indivíduos de grau 1 , com correlações significativas $P I_{\text {máx }}(r=0,52$ e $p=0,036)$ e $P E_{\text {máx }}(r=0,51$ e $p=0,042)$. Conclusão: Indivíduos com sequelas de hanseníase apresentaram comprometimento da força muscular respiratória e da capacidade funcional de exercício. As pressões respiratórias máximas se apresentaram como um fator independente na alteração do desempenho no teste de capacidade funcional de exercício.

Palavras-chave: Hanseníase. Exercício. Testes de função respiratória.

\section{Introduction}

Approximately two to three million individuals have some degree of physical impairment as a result of this disease and about $20 \%$ of individuals treated for leprosy or leprosy may present physical disabilities and psychosocial constraints, they often need some kind of intervention in rehabilitation and / or continuity of medical care (1).

Injuries in sensory nerve fibers, motor and autonomic limb result in loss of proprioception, paresthesias, contractures and deformities in the feet, which are associated with perceived limitations in walking and standing position (2). A recent study by Slim et al. (3) showed that the physical disabilities caused by leprosy affect people's lives in the areas of daily life, routines and work activities.

The functional exercise capacity in patients with leprosy was impaired in the study of Slim et al. (3) showing a smaller distance through the 6MWD, when compared to normal individuals, and even lower, the greater the degree of disability. Determinants such as strength of dorsal-flexors and ankle range of motion at the metatarsophalangeal extension muscles showed independent and direct relationship in functional exercise capacity.

The functional exercise capacity also has a direct relationship with cardiorespiratory function. In healthy subjects, the impairment of lung volume and capacity results in decreased pulmonary ventilation and perfusion, predisposing to the risk of respiratory complications (4).

Maximal respiratory pressures (inspiratory and expiratory) have a direct effect on pulmonary function, responsible for the effective contraction of the muscles involved in breathing and, through them, generate difference gradients of pressure by promoting adequate respiratory system lung volumes. Changes in respiratory pressures also generate lower volumes and reduced lung capacity (4).

A healthy pulmonary system interacts directly with the cardiac function and functional exercise 
capacity, allowing individuals to a healthy physical conditioning and fitness in daily, physical labor, and life activities (5).

Studies with other populations with chronic diseases found a relationship between pulmonary function and functional exercise capacity. Vasconcellos et al. (6) demonstrated a positive correlation between respiratory muscle strength and functional exercise capacity in sedentary older and Simões et al. (7) demonstrated a correlation between muscle weakness of the lower limbs and respiratory performance of functional exercise capacity in individuals with chronic obstructive pulmonary disease.

There is no evidence from studies that explore the relationship of respiratory variables with functional exercise capacity in patients with leprosy. It is then necessary for neural commitment and disabling this condition, its investigation.

\section{Method}

\section{Participants}

This study was conducted by the Division of Physical Therapy and Rehabilitation Center of the Universidade Estadual do Oeste do Paraná. Twenty patients with confirmed diagnosis of leprosy, men and women, who were in attendance at physiotherapy service, were evaluated. Inclusion criteria: Individuals with sequelae of leprosy, aged between 18 and 80 years, regardless of whether the first or the last query, time of diagnosis, complaints or pain, presence of disabilities, and if present, regardless of their severity. Exclusion criteria: Individuals diagnosed with cognitive disorders previously associated; individuals with unconfirmed diagnosis; reactional states that make it impossible to carry out evaluations; individuals who had neurological sequelae of disabling diseases, trauma-orthopedic, rheumatologic or other affiliates not caused by leprosy. Twenty five individuals matched for age and gender comprised the control group. There were not included in both groups subjects with myocardial revascularization for less than six months, lower limb musculoskeletal limitations that would preclude performing the functional tests, symptomatic cardiovascular disease, chronic obstructive pulmonary disease (COPD), current or previous smoking, hypertension uncontrolled, acute myocardial infarction or stroke for less than six months and individuals who regularly participate in any physical activity program. All individuals who participated from the study were informed about the proposed procedures and possible risks and signed the ethical consentient. The study was approved by the protocol CEP/Unioeste 412/2011.

\section{Physical examination}

Physical examination and assessment of the degree of disability of individuals were performed according to the criteria of the Brazilian Ministry of Health (8). The identification of neurological damage was done by neurological evaluation and inspection of the eyes, nose, hands and feet, palpation of peripheral nerve trunks, muscle strength evaluation and assessment of sensibility in the eyes, upper and lower limbs.

Inspection of the eyes, nose, upper and lower limbs: It consisted of asking the subject about the symptoms: burning, itching, blurred vision, dry eyes, heavy eyelids, tearing, or other symptoms. It were observed the presence of nodules, infiltration, discharge, redness (hyperemia), absence of eyebrows, inverted eyelashes, eversion and collapse of the lower eyelid, or corneal opacity; and possible changes in contour, size and reaction of the pupils, and they presented themselves black or whitish.

We conducted inspection of the nose, on skin conditions, mucosa of the nasal septum, and possible perforation of the nasal septum, collapse of the nose or other characteristic signs of the disease. Mucosa was examined searching for possible changes in color, moisture (too much fluid or dryness), and presence of crusts, atrophy, infiltration or mucosal ulcers.

Upon inspection of the upper limbs were asked about the possible reduction in muscle strength, numbness, or other symptoms. It was also included to check for dryness, calluses, cracks, wounds, scars, muscle atrophy and bone resorption (loss of one or more phalanges of fingers, or part of one).

Inspection of the lower limbs understood research on the possible existence of pain, numbness, and loss of strength, swelling, or other symptoms. It was verified the presence of dryness, calluses, cracks, wounds, ulcers, scars, bone resorption, muscle atrophy and gait. 
Palpation of peripheral nerve trunks: The researcher was positioned in front of the individual, positioning it according to the specific description of the technique of palpation of each nerve. The nerve is palpated with the fingertips of the second and third fingers, sliding them on the bone surface, watching the path of the nerve, in order from top to bottom. It was verified during palpation presence or absence of spontaneous pain on the path of the nerve, feeling of shock, thickening nerve palpated with the corresponding nerve opposite, changes in consistency (softening or hardening), and change in nerve shape with presence of abscesses, nodules and adhesions.

Muscular strength evaluation: Conducted tests of muscular strength in the upper and lower limbs and rated according to the scale of the MRC (Medical Research Council), when grade 5 is considered strong, and the remainder $(4,3$ and 2 ) reduced strength and grade 1 and 0 with lack of muscle strength .

Joint mobility: checked joint mobility of the hands and feet by active and passive movements. We asked the subject for active movement of the joints of the hands and feet and followed by passive movement by the examiner. With the other hand, were performed movements of flexion and extension.

Evaluation of the sensitivity of the eyes, upper and lower limbs: the procedures were explained and demonstrated in a test area of skin with normal sensitivity, requesting to remain with closed eyes. Predefined points were tested by tapping with a ballpoint pen and esthesiometry, asking to answer "yes" if so, in the presence of sensitivity and "no" in the absence of the same. Visual acuity was also tested by the Snellen chart.

\section{Functional exercise capacity}

The 6MWD was conducted in accordance with the recommendations of the American Thoracic Society (ATS) (9). Participants were instructed to walk as fast as possible without running or jogging on a flat corridor of 30 meters, covered with good ventilation, lighting and mild climatic conditions. The corridor was delimited by cones and boundaries every three meters have been made. Standardized phrases of encouragement were spoken to the participants every minute. The instructions were given before the test start and interruption criteria were severe dyspnea, clarify that volunteers could stop the test for any reason they thought relevant. The walked distance was considered for analysis. Results were quantified in absolute values and in percentage of predicted.

\section{Spirometry}

For spirometry the Microlab 3300 spirometer By Micromédica $\operatorname{Ltd}^{\circledR}$ was used. The maneuver to spirometry consists of a deep inspiration followed by forced expiratory maneuver, maintained until the individual no longer tolerate, or until the acceptance criteria proposed by the Guidelines for Pulmonary Function Tests of the Brazilian Thoracic Association (BTA) (10). All subjects performed at least three forced vital capacity maneuvers. Forced vital capacity (FVC), forced in one second $\left(\mathrm{FEV}_{1}\right)$ and $\mathrm{FEV}_{1} / \mathrm{FVC}$ expiratory volume. From these maneuvers the numerical values of the following variables were obtained. The predicted values were obtained from the reference values for adults reported by the BTA.

\section{Manovacuometry}

The maximal inspiratory pressure (MIP) and maximal expiratory pressure (MEP) were measured by a digital manometer Microhard MVD 500. For measurement of maximal respiratory pressures, subjects were in a sitting position, with the nostrils occluded with a nose clip and fitted with an outlet circuit to prevent the cheek muscles interfere in the results. The subjects were instructed to exhale to residual volume (RV) or inhale to total lung capacity (TLC) before being encouraged to inhale / exhale with maximum effort into the mouth to measure the MIP and MEP respectively. Were also instructed to avoid the collapse of the cheeks during measurement, raising the pressure of the oral cavity, generated exclusively by the contraction of facial muscles with closure of the glottis (11). Were performed three to five maximal acceptable and reproducible maneuvers (difference of $10 \%$ or less between efforts), with an interval of rest between efforts for about 1 minute, and recorded the highest value. The equation of Neder et al was adopted to calculate the predicted values (12). 
Statistical analysis

The variables were tested for normal distribution using the Pearson Test of Asymmetry. For analysis between groups used the Student $t$ test. Pearson correlation coefficients were used to investigate associations between the data found on physical examination, testing of functional exercise capacity and pulmonary function. We used multiple linear regression to measure the contribution of independent variables that showed a significant positive correlation. Residual analysis was used to search for violations of necessary assumptions in multiple regression in terms of linearity, equality of variance, independence of errors, normality of the data and influence (Cook's Distance) to that same group. Statistically significant values were considered with $\mathrm{p}<0.05$ for all tests. Statistical analysis was performed using Minitab version 15.

\section{Results}

The sample consisted of 20 (HG Hansen Group) subjects $15(75 \%)$ male. The data obtained showed a mean age of $57.2 \pm 12$ years, weight $73.3 \pm 6 \mathrm{~kg}$ and height of $1.68 \pm 0.1 \mathrm{~m}$. The control group (CG) has similar characteristics to other groups. According to the classification of the grade of disability by the Brazilian Ministry of Health, 15 (75\%) subjects had grade 1 (GD1) and five (25\%) individuals disability grade 2 (GD2). The data characterizing the sample and the degree of disability are presented below (Table 1).

According to the physical examination regarding the neural functions and its complications, we observed impairment related to face, palpation of the nerves of the upper and lower limbs, muscle strength of upper and lower limbs and also the sensitivity of the hands and feet.

Of the 20 patients evaluated, 18 (96\%) had normal pulmonary function test, and two patients (4\%) had mild restrictive lung disturb and those two with the corresponding grade 2 disability scale. When investigated the control group all subjects had values within normal limits (Table 2). There was no statistical difference between these groups.

Regarding the maximal respiratory pressures, both maximal inspiratory pressure and maximal expiratory pressure on average, showed below values, indicating respiratory muscle impairment. For
MIP was obtained averaging $-71.0 \pm 31 \mathrm{cmH}_{2} \mathrm{O}$ and MEP of $89.0 \pm 22 \mathrm{cmH}_{2} 0$. The predicted average percentage achieved for MIP was $72 \%$ and $83 \%$ of the MEP. When compared to physical disability grade, maximum respiratory pressures continue to provide muscle weakness and further decrease in respiratory pressures the greater are the grade of disability. When comparing the averages of HG with CG they are lower and CG presents normal values (Table 3).

According to the results of the $6 \mathrm{MWD}$, the distance had an average of $404.0 \pm 92 \mathrm{~m}$, representing $73 \%$ of the distance expected by them in accordance with the guideline by ATS (9). The results of CG showed average of $485.0 \pm 43 \mathrm{~m}$ amounting to $87 \%$ of the expected distance when compared with the predicted values. Demonstrating the data according to the grade of physical disability, individuals with grade 1 have similar characteristics to the HG, whereas when the level reaches 2 observed short course on distance traveled. When comparing the mean of the groups HG, GD1 and GD2 with the CG, they showed lower values (Table 3 ).

In investigating possible associations between alterations found on physical examination and their respective grades of disability, with the values of the walking distance by individuals, positive correlations were found in various items, although with no statistically significant power.

In the correlation between maximal respiratory pressures and functional exercise capacity, statistically significant and positive values were found when comparing the MIP with the 6MWD in HG ( $\mathrm{r}=0.49$ and $p=0.025$ ) and also the MEP in HG on the 6MWD $(\mathrm{r}=0.53$ and $\mathrm{p}=0.004)$. The same evidence is found in maximal respiratory pressures of individuals in grade 1 , MIP with significant correlations $(\mathrm{r}=0.52$ and $\mathrm{p}=$ $0.036)$ and MEP ( $r=0.51$ and $p=0.042)$ (Table 4).

Applied multiple linear regression to examine the independent contribution of MIP and MEP in performance in the 6MWD distance. The results showed a contribution of 24.8\% (MIP) and 29\% (MEP) of the total required. When analyzed the contribution of the two pressures in the performance of functional exercise capacity revealed a $32.7 \%$ (Table 5).

Spirometric data when associated with 6MWD showed significant correlation between $\mathrm{FEV}_{1}$ $(\mathrm{r}=0.85$ and $\mathrm{p}=0.065)$ and $\mathrm{FVC} / \mathrm{FEV}_{1}(\mathrm{r}=0.40$ and $\mathrm{p}=0.50$ ) corresponding to the grade 2 disability with walking distance in the same grade, but without statistical significance. 
Table 1 - Characteristics of the sample

\begin{tabular}{|c|c|c|c|c|}
\hline & HG & GDl & GD2 & CG \\
\hline & Mean \pm SD & Mean \pm SD & Mean \pm SD & Mean \pm SD \\
\hline Body Mass (kg) & $73.3 \pm 6.3$ & $72.93 \pm 7.1$ & $75.05 \pm 5.7$ & $72.11 \pm 11$ \\
\hline Height (m) & $1.68 \pm 0.8$ & $1.67 \pm 0.1$ & $1.67 \pm 0.1$ & $1.63 \pm 0.1$ \\
\hline Age (years) & $57.20 \pm 12$ & $57.63 \pm 12$ & $56 \pm 16$ & $68 \pm 7$ \\
\hline Gender (M/F) (\%) & $75 / 25$ & $82 / 18$ & $75 / 25$ & $36 / 64$ \\
\hline
\end{tabular}

Note: kg: kilograms; m: meters; \%: percentage; HG: Hansen Group; GD1: Group Disability Grade 1; GD2: Group Disability Grade 2; CG: Control Group.

Source: Research data.

Table 2 - Spirometric data

\begin{tabular}{|c|c|c|c|c|c|c|c|c|}
\hline & \multicolumn{2}{|l|}{ HG } & \multicolumn{2}{|l|}{ GD1 } & \multicolumn{2}{|l|}{ GD2 } & \multicolumn{2}{|l|}{ CG } \\
\hline & Mean \pm SD & $\%$ & Mean \pm SD & $\%$ & Mean \pm SD & $\%$ & Mean \pm SD & $\%$ \\
\hline FVC (pred) & $3.23 \pm 1.0$ & 89 & $3.32 \pm 0.8$ & 91 & $2.57 \pm 0.7$ & 81 & $2.76 \pm 0.7$ & 96 \\
\hline $\operatorname{VEF}_{1}$ (pred) & $87.40 \pm 7.2$ & 112 & $88.94 \pm 6.6$ & 108 & $83.0 \pm 9.3$ & 117 & $89.0 \pm 7.1$ & 117 \\
\hline FVC/VEF ${ }_{1}$ (pred) & $2.77 \pm 0.8$ & 95 & $2.90 \pm 0.6$ & 95 & $2.29 \pm 1.2$ & 91 & $2.26 \pm 0.6$ & 104 \\
\hline $\mathrm{FEF}_{25 \%}$ (pred) & $1.53 \pm 0.5$ & 97 & $1.70 \pm 0.5$ & 96 & $1.11 \pm 0.4$ & 90 & $1.41 \pm 0.7$ & 95 \\
\hline
\end{tabular}

Note: FVC: forced vital capacity; $\mathrm{VEF}_{1}$ : volume expiratory forced in one second; $\mathrm{FVC}_{\mathrm{VEF}}$ : ratio of forced vital capacity and volume expiratory forced in one second; $\mathrm{FEF}_{25 \%}$ : forced expiratory flux in twenty five percentage of the maneuver; SD: standard deviation; \%: percentage; pred: percentage of predicted.

Source: Research data.

Table 3 - Respiratory pressures and 6MWD

\begin{tabular}{|c|c|c|c|c|c|c|c|c|}
\hline & \multicolumn{2}{|l|}{ HG } & \multicolumn{2}{|l|}{ GD1 } & \multicolumn{2}{|l|}{ GD2 } & \multicolumn{2}{|l|}{ CG } \\
\hline & Mean \pm SD & $\%$ & Mean \pm SD & $\%$ & Mean \pm SD & $\%$ & Mean \pm SD & $\%$ \\
\hline MIP & $71.0 \pm 31$ & 72 & $74.0 \pm 32$ & 69 & $57.0 \pm 27$ & 78 & $89.0 \pm 15$ & 90 \\
\hline MEP & $89 \pm 22$ & 83 & $92.0 \pm 21$ & 82 & $71.0 \pm 18$ & 91 & $109.0 \pm 17$ & 100 \\
\hline 6MWD & $404 \pm 92$ & 73 & $418.0 \pm 92$ & 73 & $353.0 \pm 63$ & 70 & $485.0 \pm 43$ & 87 \\
\hline
\end{tabular}

Note: 6MWD: six minute walking distance in meters; MIP: maximal inspiratory pressure in $\mathrm{cmH}_{2} 0$; MEP: maximal expiratory pressure in $\mathrm{CmH}_{2} \mathrm{O}$; SD: standard deviation; \%: percentage.

Source: Research data. 
Table 4 - Correlations between maximal respiratory pressures and 6MWD

\begin{tabular}{|c|c|c|c|c|c|c|}
\hline & \multicolumn{2}{|c|}{ HG } & \multicolumn{2}{|c|}{ GD1 } & \multicolumn{2}{|c|}{ GD2 } \\
\hline & $r$ & p-value & $r$ & $\mathrm{p}$-value & $r$ & $\mathrm{p}$-value \\
\hline MIP & $0.49 *$ & 0.025 & $0.52^{\star}$ & 0.036 & 0.034 & 0.96 \\
\hline MEP & $0.53^{*}$ & 0.004 & $0.51^{*}$ & 0.042 & 0.14 & 0.82 \\
\hline
\end{tabular}

Note: ${ }^{*}: p<0.05$.

Source: Research data.

Table 5 - Independent contribution of maximal respiratory pressures in 6MWD performance

\begin{tabular}{|c|c|c|}
\hline Model Adjusted & $\mathbf{R}^{2}$ & SD from Model S \\
\hline $6 M W D=299.44+1.46 \operatorname{MIP}\left(0.00^{\star}\right)\left(0.026^{\star}\right)$ & $24.8 \%$ & 82.03 \\
\hline $6 \mathrm{MWD}=206.09+2.22 \operatorname{MEP}\left(0.013^{\star}\right)\left(0.014^{\star}\right)$ & $29 \%$ & 79.71 \\
\hline 6 MWD $=213.72+1.53$ Pimáx +0.75 MEP $\left(0.012^{\star}\right)(0.17)(0.34)$ & $32.7 \%$ & 79.85 \\
\hline
\end{tabular}

Note: significance tests of the parameters are given $5 \%$ probability.

Source: Research data.

\section{Discussion}

The leprous neuropathy is a finding that accompanies all clinical forms of the disease, with signs and symptoms of greater or less extent in each of them (13). In all forms of leprosy occurs the presence of the bacilli in the nerves, which is housed in the Schwann cells in both myelinated and demyelinated axons. These not inflammatory phenomena promote early demyelination, occurring even before the body perceives the presence of the bacillus, being called parasitation (14).

With disease progression neural involvement is exacerbated by pain and thickening of peripheral nerves, loss of sensation in the areas innervated by these nerves, especially in the eyes, hands and feet, and loss of strength in muscles innervated by these nerves especially in eyelids and the upper and lower members (8).

These changes are evident in the research, where physical disability grade 1 was found in $75 \%$ of individuals that corresponds to changes in the strength and sensitivity of both upper and lower limbs. Chronic diseases such as diabetes mellitus, syringomyelia, chronic injuries or disorders of the peripheral nerves as chronic alcoholism also show these findings (15).

When the neural damage is not treated can cause disabilities and deformities by abnormal sensitivity in the areas innervated by nerves affected (8), correlating with the remaining individuals (25\%) having physical disability grade 2 in the study.

Data found in this study refer to the decrease in respiratory muscle strength, indicating that the neural damage is also related to the respiratory system by promoting a reduction in respiratory muscle strength. Some neurological diseases such as multiple sclerosis, which also reach the Schwann cell, evolve with respiratory muscle weakness and its commitment increases with disease progression $(16,4)$. Amyotrophic lateral sclerosis also evident loss of respiratory muscle strength, through the involvement of the motor neuron that progresses to respiratory failure $(4,17)$. When compared to CG values (absent respiratory neural damage) they are within the normal range.

In this study, the reduction in respiratory muscle strength may be related to chronic disease in which the affected individuals already have the disease sequelae and high levels of physical disability. When 
comparing the mean of maximal respiratory pressures can be observed that the pressures reduces with the disease progression: MIP grade 1: $-74 \mathrm{cmH}_{2} \mathrm{O}$ versus $-54 \mathrm{cmH}_{2} \mathrm{O}$ in grade 2 and grade $1 \mathrm{MEP}: 92$ $\mathrm{cmH}_{2} \mathrm{O}$ versus $71 \mathrm{cmH}_{2} \mathrm{O}$ in grade 2 .

When analyzed spirometric values they are normal, but when comparing the mean per grade of physical disability is noticed the gradual decline in volumes and justifies the two individuals who had restrictive lung disturb because them presents physical disability grade 2 , beyond this same group also exhibit reduced maximal respiratory pressures, which would also compromise the generation of pressures and volumes. When the data are related to the CG notes normal values.

Studies investigating the functional exercise capacity in this population are limited. According to ATS (9) adults without functional limitations are able to travel longer distances compared to individuals with leprosy. The mean distance for healthy adult men is $576.0 \mathrm{~m}$ and $494.0 \mathrm{~m}$ for healthy adult women, which differs from the present study population.

Functional exercise capacity in this sample were compromised in individuals with leprosy sequelae demonstrated by reduced 6MWD (mean $404.0 \pm 92 \mathrm{~m}$ ). The mean was higher when compared to the study of Slim et al. with $387.0 \mathrm{~m}$ (3), justified by the difference in number of subjects in each grade of physical disability, where the current sample met more individuals with grade 1 (15 individuals) and in the author's larger group with grade 2 (27 individuals).

In a study by Peres (18) functional exercise capacity was measured by the Shuttle Walking Test showing mean of $326.0 \mathrm{~m}$ distance in individuals with leprosy, lower than this study justified by the different methodology presented. When compared with other chronic diseases like diabetes, which is also evident peripheral neuropathy, the walking distance was higher in this study ( $404 \mathrm{~m}$ versus $317 \mathrm{~m}$ ) (19). Regarding the CG leprosy subjects also showed lower values.

The grade of disability can be a predictor of poor distance due to musculoskeletal and neurological disorders. The decrease in strength and sensitivity of the lower limbs, deformities, atrophies and other dysfunctions slows the velocity of gait reducing the walking distance. Musculoskeletal disorders, compromised health status and chronic diseases can reduce the walking distance during the test (9). When comparing the distance by each group demonstrates a reduction in the functional exercise capacity with the progression of disability (Grade 1: $418 \mathrm{~m}$ versus Grade 2: $353 \mathrm{~m}$ ). Positive correlations, but not statistically significant were found in grade 1 in the sections pain and palpation of the peroneal nerve that could be associated with reduced performance on the test. Moreover, positive correlations but statistically insignificant were found in grade 2 : dryness and sores in the nose, change in visual acuity, pain on palpation on the ulnar nerve and abnormal sensitivity in the upper limbs as possible determinants of low performance in the test.

Maximal respiratory pressures were shown to be independent determinants of performance impairment in functional exercise capacity. In the present study there was a positive correlation between maximal respiratory pressures and the walking distance, promoting shorter walking distance when compared to healthy subjects (MIP $r=0.49$, $\mathrm{p}=0.025$ and MEP $\mathrm{r}=0.53, \mathrm{p}=0.004)$. Associations are evident both in the HG individuals and in those GD1. As much as inspiratory-expiratory muscle weakness proved to be a predictor of reduced performance in functional exercise capacity test. The adjusted model showed association of $24.8 \%$ of MIP with performance on the 6MWD and 29\% of MEP in 6MWD performance.

Studies in other populations have also found similar data as Vasconcellos et al. (6) which evaluated the MIP, MEP and functional exercise capacity by 6MWD among sedentary elderly. The results showed a positive and statistically significant correlation $(r=0.45$ and $p=0.005$ ) between the walking distance and inspiratory muscle strength. Simões et al. (7) showed positive and statistically significant correlations between the functions of the respiratory muscles and weakness of the lower limbs, as well as the physical parameters of these muscles and functional exercise capacity in the elderly. Already in COPD patients, the training of the respiratory muscles and the quadriceps proposed by Trevisan (20) has proven beneficial improving in the functional performance of patients in the walk test, suggesting the use of respiratory and peripheral muscle strength as an adjunct in the treatment of these individuals.

From the findings, we suggest further studies that focus on the implementation of rehabilitation protocols for both lung function and for increments of functional exercise capacity for patients with sequelae of leprosy, and public health policies that 
focus on primary care, secondary and tertiary care in this population.

\section{Conclusion}

This study aimed to investigate the maximal respiratory pressures and pulmonary function in patients with sequelae of leprosy and their correlation with functional exercise. In this sample, individuals with sequelae of leprosy characterized with physical disability grades 1 and 2 , showed a decrease of maximal respiratory pressures and reduced functional exercise capacity. The results showed a positive and statistically significant correlation between the walking distance and respiratory muscle strength. Maximal respiratory pressures were found to be predictors of poor performance in functional exercise capacity in this population.

\section{References}

1. Deepack S. Answering the rehabilitation needs of leprosy affected persons in integrated setting through primary health care services and community based rehabilitation. Indian J Lepr. 2003;75(2):127-42.

2. Brakel V, Anderson AM. Impairments and Disability in Leprosy: in search of the missing link. Indian J Lepr.1997;69:361-76.

3. Slim FJ, Keukenkamp R., van Schie CH, Faber WR, Nollet F. Foot Impairments and limitations in walking activities in people affected by leprosy. J Rehabil Med. 2011;43(1):32-8.

4. Paschoal IA, Villalba WO, Pereira MC. Insuficiência respiratória crônica nas doenças neuromusculares: diagnóstico e tratamento. J bras pneumol. 2007;33(1):81-92.

5. Arcêncio L, Souza MD, Bortolin BS, Fernandes ACM, Rodrigues AJ, Evora PRB. Cuidados pré e pós-operatórios em cirurgia torácica: uma abordagem fisioterapêutica. Rev Bras Cir Cardiovasc. 2008;23(3):400-10.

6. Vasconcellos JAC, Britto RR, Parreira VF, Cury AC, Ramiro SM. Pressões respiratórias máximas e capacidade funcional em idosas assintomáticas. Fisioter Mov. 2007;20(3):93-100.
7. Simões LA, Dias JMD, Marinho KC, Pinto CLLR, Britto RR. Relação da função muscular respiratória e de membros inferiores de idosos comunitários com a capacidade funcional avaliada por teste de caminhada. Rev Bras Fisioter. 2010;14(1):24-30.

8. Ministério da Saúde (Brasil). Departamento Nacional de Saúde. Serviço Nacional de Lepra. Manual de Leprologia. Rio de Janeiro; 2002.

9. American Thoracic Society Statement. Guidelines for six-minute walk test. Am J Respir Care Med. 2002; 166(1):111-7.

10. Pereira CAC. Testes de função pulmonar. Brasília: Sociedade Brasileira de Pneumologia e Tisiologia; 2001.

11. Pereira CAC, Neder JA (Ed.). Diretrizes para testes de função pulmonar. J. Pneumol. 2002;28(Supl 3):1-238.

12. Neder JA, Andreoni S, Lerario MC, Nery LE. Reference values for lung function tests. II. Maximal respiratory pressures and voluntary ventilation. Braz J Med Biol Res. 1999;32(6):719-27.

13. Rafael AC. Pacientes em tratamento e pós-alta em hanseníase: estudo comparativo entre os graus de incapacidade preconizados pelo Ministério da Saúde correlacionando-os com as Escalas SALSA e Participação Social [dissertação]. Brasília: Universidade de Brasília - Faculdade de Ciências Médicas; 2009.

14. Freitas MRG, Nascimento OJM, Quaglino EAM, Oliveira A, Hahn MD. Small-fiber polyneurophaty in leprosy without skin changes: study of 17 cases. Arq Neuropsiquiatr. 2003;61(3):542-6.

15. Ministério da Saúde (Brasil). Secretaria de Vigilância em Saúde. Departamento de Vigilância Epidemiológica. Cadernos de prevenção e reabilitação em hanseníase: n. 1. 3. ed. Brasília: Ministério da Saúde, 2008.

16. Araújo RL, Rebouças F, Fragozo YD. Possível associação entre a fadiga física e o grau de força dos músculos respiratórios na Esclerose Múltipla. Rev Neurocienc. 2007;15(3):207-10.

17. Xerez DR. Reabilitação na esclerose lateral amiotrófica: revisão de literatura. Acta Fisiatr. 2008;15(3):182-8.

18. Peres CPA. Avaliação da capacidade funcional de exercício em indivíduos com sequelas de hanseníase. Fiep Bulletin. 2011 [cited 2014 Feb 13];81(2). Available from: http://www.fiepbulletin.net/index.php/ fiepbulletin/article/view/327/601 
19. Dolan NC, Liu K, Criqui MH, Greenland P, Guralnik JM, Chan C, et al. Peripheral artery disease, diabetes, and reduced lower extremity functioning. Diabetes Care. 2002;25(1):113-20.
20. Trevisan ME, Porto AS, Pinheiro TM. Influência do treinamento da musculatura respiratória e de membros inferiores no desempenho funcional de indivíduos com DPOC. Fisioterapia e Pesquisa. 2010;17(3):209-13.

Received: 03/20/2013

Recebido: 20/03/2013

Approved: $11 / 18 / 2013$

Aprovado: 18/11/2013 